\title{
La formación del profesional universitario en el marco del desarrollo sostenible ${ }^{(1)}$
}

\author{
Daniel Eduardo Martínez \\ Universidad Nacional de La Matanza, San Justo, Argentina \\ $\bigotimes$ rector@unlam.edu.ar
}

Marcelo Claudio Perissé

Universidad Nacional de La Matanza, San Justo, Argentina

$\bigotimes$ mcperisse@gmail.com

\section{Silvia Marisa Rampello}

Universidad Nacional de La Matanza, San Justo, Argentina

\srampello@unlam.edu.ar

Fecha de recepción: 09/10/2020 - Fecha de aceptación: 04/11/2020

\begin{abstract}
Cómo citar este artículo: Martínez, D.E.; Perisse, M.C. y Rampello, S.M. (2021). La formación del profesional universitario en el marco del desarrollo sostenible. Revista Perspectivas de las Ciencias Económicas y Jurídicas. Vol. 11, № 2 (julio-diciembre). Santa Rosa: FCEyJ (UNLPam); EdUNLPam; pp. 207-213. ISSN 2250-4087, e-ISSN 2445-8566 DOI http://dx.doi.org/10.19137/perspectivas2021-v11n2c01
\end{abstract}

(1) Este trabajo fue elaborado con la colaboración de los becarios Nicolás Bonfanti e Ingrid Colman. 


\section{Fundamentación}

Con el fin de promover la creación de empresas fundadas y llevadas adelante por alumnos universitarios que puedan generar empleo e ingresos significativos en relación con el producto bruto interno y que, por lo tanto, tengan un impacto positivo en el medio en el que se insertan, hemos planteado un proyecto de investigación cuyo objetivo es desarrollar estrategias para lograr una formación emprendedora en estudiantes universitarios que se constituyan en profesionales y emprendedores capaces de conducir de manera exitosa los emprendimientos industriales en los que participen.(2) Este trabajo se concentra en describir dicho proyecto, el estado de la cuestión, objetivos, hipótesis y metodología.

\subsection{La universidad y el trabajo profesionalizado para el bienestar social}

La educación universitaria, en el marco de la ciencia y la tecnología, es el motor del crecimiento económico para el progreso social. La comunidad científica, integrada por docentes-investigadores, ${ }^{(3)}$ ha de constituirse a partir de formadores de profesionales con una visión (sistematizada en leyes y teorías) que les permita elaborar y alcanzar los objetivos y las metas que conducen a la prosperidad social. Esta prosperidad social precisa ser plasmada en el crecimiento económico y, además, debe estar acompañada por un desarrollo social que se concrete, a su vez, en una distribución equitativa del ingreso. Si esta meta pudiera cumplirse, la capacitación universitaria para el trabajo profesionalizado de los agentes económicos, se constituiría en un incentivo de la retribución en la medida que lograría mejorar la efectividad del sistema económico y el bienestar social del agente. Milton Friedman (1957) expresa su hipótesis de ingresos permanentes de que el bienestar de un individuo depende de la satisfacción por sus ingresos actuales y de la expectativa en la variación de sus ingresos futuros (Perissé, 2018a).

\subsection{La universidad en una red global de cooperación productiva}

En principio, podemos decir que, en un sistema económico, los agentes (trabajadores, capitalistas, financistas y rentistas) pretenden mejores salarios, mejores beneficios, mayores rendimientos financieros y mayor renta, respectivamente. A su vez, todos y cada uno de ellos, como consumidores, buscan precios ventajosos. Esa pretensión de beneficios conducentes a la prosperidad social que se da bajo la lógica de la retribución por la oferta de sus factores de producción en la dimensión de la empresa, y por los mejores precios alcanzados en la demanda de bienes y servicios en la dimensión de la familia, hoy se realiza bajo nuevas formas derivadas de la globalización (Perissé, 2018a).

(2) El proyecto se encuentra radicado en el Departamento de Ciencias Económicas de la Universidad Nacional de La Matanza. https://economicas.unlam.edu.ar/descargas/4_B221.pdf

(3) Particularmente nos referimos aquí a los campos del conocimiento relacionados a la economía política. 
El proceso mundial de globalización económica mencionado se presenta como "el motor" que impulsa al crecimiento económico y es un proceso de internacionalización del capital conducente a nuevas formas de organización económica. Este es el caso del modelo de producción flexible toyotista, del comercio mundial sustentado en las nuevas tecnologías de la información y registros de propiedad intelectual (marcas, patentes de invención, modelos de utilidad, transferencia de tecnología) y de los nuevos instrumentos financieros como la titularización, el swap y los derivados.

Ahora bien, estos nuevos "impulsos" derivados de la internacionalización del capital, con su dinámica, procuran nuevas posiciones de equilibrio y, por ende, provocan lógicos desequilibrios. Esencialmente producen, y se percibe con clara evidencia empírica, una inequitativa relación social de producción (conocidos y tratados en economía bajo distintos términos, como "crematística", "auri sacra fames", u "ofelimidad", entre otros). Esto hace que, en la necesidad de trabajar sobre las inequidades expresadas en dichos desequilibrios, la universidad se presente como un clúster social y económico que puede promover una nueva forma de red en torno a las cadenas de valor y que, consecuentemente, permite la revalorización del capital como relación social de la producción. Allí se debe priorizar la generación del conocimiento como factor productivo que conduzca al desarrollo socioeconómico. También se debe asegurar que no se busquen hallazgos de combinaciones óptimas para determinados recursos y factores productivos que se deriven de procesos analísticos construidos con "alquimias mágicas" que se sustenten en el "sentido común" de los mercados (Perissé, 2011).

En esta configuración de clúster universitario, que contiene una red de cooperación productiva, a cada miembro emprendedor se le garantiza el acceso a todos los recursos de la red. Por lo tanto, el riesgo de cada emprendedor, especialmente en medianos y grandes proyectos, será amortiguado entre los miembros de la red. Además, entre algunas otras ventajas de una red de cooperación, la universidad puede mejorar los grados de eficiencia, eficacia y efectividad que demanda cada emprendimiento (Schumpeter, 1997). Esto lo podrá hacer por su capacidad de proveer los saberes necesarios para la certificación de las nuevas empresas, aumentar la confianza en los procesos administrativos y constituir -a través de la tecnología de la información y las comunicaciones- procesos que permitan articular los datos, la información y los conocimientos científicos y tecnológicos que todo sistema requiere (Benecke, 1973; Perissé, 2018b).

En este sistema de innovación abierta propuesto por Henry Chesbrough (2012), la universidad, a través de los programas y proyectos tecnológicos y sociales que se han de implementar conjuntamente con los emprendedores mediante planes acordados de investigación y desarrollo, se constituye como un órgano capacitado para garantizar las acciones necesarias para generar el mayor impacto en los sistemas sociales y económicos. Se espera, así, que dichas acciones conduzcan al desarrollo socioeconómico regional (Perissé, 2019). 


\subsection{La universidad en un modelo de gestión e innovación productiva}

En el marco de la innovación y transferencia tecnológica, en donde distintos agentes económicos, sociales y políticos forman estrategias para el desarrollo socioeconómico, presentamos un modelo de gestión tecnológica e innovación productiva, que comprende a los procesos de ideación, creación, planeamiento del negocio y financiamiento del proyecto. En este contexto, se busca describir un modelo económico que permita poner en valor al conocimiento generado para la creación o transformación de productos (bienes o servicios) de alto contenido tecnológico (high-tech), que sean soluciones adaptables a las demandas de los mercados globales. Sus características principales son: ser un incentivo para las actividades de Investigación y Desarrollo, contar con un proceso simple de patentamiento para proteger las invenciones y atender a la estandarización que facilite la adopción masiva del producto por la industria.

\section{Objetivos del proyecto}

El proyecto que aquí describimos se propone los siguientes objetivos:

- Elaborar soluciones innovadoras a problemas sociales concretos que conlleven efectos directos sobre el crecimiento económico y, consecuentemente, generen un alto impacto en el desarrollo social.

- Constituir un espacio académico de Investigación y Desarrollo que permita, bajo una base científica y tecnológica, la aceleración de las transformaciones estructurales de los sistemas económicos con el fin último de alcanzar y sustentar el desarrollo social.

- Llevar adelante las acciones resultantes del programa de investigación y de los proyectos que lo constituyen, para formar profesionales universitarios con capacidades innovadoras y emprendedoras, y para que estos se constituyan en referentes intelectuales de la comunidad científica donde actúan.

\section{Nuestra hipótesis}

Los cambios en el crecimiento económico dependen principalmente de los impulsos originados por el gasto y la inversión pública y privada, dados en un contexto de internacionalización de los capitales, como así también de la capacidad de propagación o difusión de ellos entre las distintas fuerzas productivas (trabajadores, capitalistas, financistas, rentistas y estado). Entonces, para impulsar el crecimiento económico, se precisará no solo de la capacidad de financiamiento de las empresas, sino también de una cooperación productiva que permita aumentar el nivel de cohesión (integración y coordinación) de los agentes económicos (productivos, financieros o bursátiles, y comerciales) en torno de las cadenas de valor, y de la adhesión a estructuras universitarias en las que se crea y gestiona conocimiento científico y tecnológico que permite transformar, por medio de la innovación, las necesidades sociales y empresariales en bienes y servicios (útiles y necesarios) que atiendan demandas conducentes al crecimiento económico y al desarrollo social. 


\section{Metodología de formación a incentivar}

Partir de la concepción de "sistemicidad" expuesta por Mario Bunge (Bunge, 2012; Araceli, 1995) y, más particularmente, del método de Jay Forrester (1961), denominado "dinámica de sistemas", permite actuar sobre la secuencia educativa tradicional introduciendo una síntesis de contenidos desde la primera etapa de un estudiante, que consiste en sumar en el proceso de aprendizaje la consideración de los hechos que preceden a su memorización por parte de los alumnos.

Dicho en otras palabras, el "aprendizaje del alumno" no se basa únicamente en la enseñanza de un docente que explica los hechos a los alumnos. Con la dinámica de sistemas, los alumnos tienen la oportunidad de explorar hechos, reunir información y crear una unidad de conocimientos más allá del aula universitaria. Además, en este contexto de la dinámica de sistemas, un docente -que, además, se ha estado formando como docente-investigador- actuará como guía de un alumno participante, y no como un simple depositario de sabiduría carente de entusiasmo y sentido de utilidad (Forrester, 1996; Perissé, 2020).

En la educación, usualmente se enseña a partir de imágenes que son representaciones estáticas del mundo real, y la mente humana toma esas imágenes, mapas y relaciones estáticas de manera muy efectiva. Pero los problemas del mundo son dinámicos, y es allí donde la mente humana tendrá dificultades para percibir y simular los cambios del sistema que se presenten a través del tiempo. Esto ocurre porque casi todas las experiencias entendibles refuerzan la creencia de que las causas están relacionadas con las consecuencias. En sistemas más complejos, la causa de una dificultad está generalmente distante tanto del tiempo como del espacio. La causa se originó mucho antes y surgió de una parte diferente del sistema de donde los síntomas aparecen. Pero, ante dicha dificultad, toda mente, ayudada con un ordenador personal y con conocimientos básicos de simulación, puede avanzar notablemente en la comprensión de tal sistema (Forrester, 1996).

Para complicar más aún las cosas, un sistema complejo generalmente presenta lo que esperamos: una causa aparente que se encuentra cerca del síntoma, en cuanto a tiempo y espacio. Sin embargo, esa causa aparente, por lo general, es un síntoma casual mediante el cual existe un pequeño apalancamiento para producir la mejora (observar el caso de asepsia de Ignaz Philipp Semmelweis). La educación actual no prepara a los estudiantes para enfrentarse a esta complejidad, de forma que a menudo son conducidos por una dirección equivocada en el complejo mundo real. Hay que reconocer que en cada mente humana se encuentra el conocimiento mundial sobre las estructuras dinámicas.

El uso del ordenador en el aula (no en un laboratorio) puede crear un ambiente de aprendizaje donde los estudiantes aprenden lo que necesitan saber mientras que los maestros les enseñan cómo hacer una simulación en clase. Antes de hacer una simulación, los estudiantes trabajan durante varias clases reuniendo 
información sobre el tema, toman notas durante las clases, perciben la relevancia de la biblioteca y leen referencias, y grupalmente planifican la simulación. Al trabajar de esta manera (adquirir y usar el conocimiento), los estudiantes recopilan el material de un estudio determinado y lo aplican en un proyecto simulando situaciones de la vida real. Esto nos ha llevado a identificar un nuevo paradigma de aprendizaje, el cual ha sido definido como "pensamiento sistémico con aprendizaje del alumno" (Brown, 1990).

En el libro Limits to Growth (2004), que ha sido actualizado recientemente como Beyond the Limits (1975), Meadows, Meadows y Randers exponen sobre el pensamiento sistémico en la educación, afirmando que el enfoque consiste de tres componentes separados e independientes: dinámica de sistemas, perspectiva teórica, y STELLA (bien puede ser otro aplicativo, como el Vensim), que es un paquete de software para crear modelos de simulación y un ordenador.

\section{Recapitulación}

En el marco de la necesidad de promover la creación de empresas que, fundadas por alumnos universitarios, generen empleo e ingresos significativos en el producto bruto interno, nos planteamos la necesidad de contar con un proyecto cuyo objetivo apunte a detectar estrategias para una formación emprendedora para estudiantes universitarios. A estos últimos los entendemos como profesionales y emprendedores con la expectativa de que puedan conducir de manera exitosa los emprendimientos industriales en los que participen.

Consecuentemente, para formar emprendedores y empresarios universitarios, será preciso constituir un espacio académico de Investigación y Desarrollo que permita, bajo una base científica y tecnológica, la aceleración de las transformaciones estructurales de los sistemas económicos con el fin último de alcanzar y sustentar el desarrollo social. Este objetivo de desarrollo socioeconómico bien puede ser alcanzado mediante la elaboración de soluciones innovadoras para problemas sociales concretos que conlleven efectos directos sobre el crecimiento económico y, consecuentemente, generen un alto impacto en el desarrollo social. (Lopes de Sá, 2008; Perissé, 2018a).

Entonces, para poder llevar adelante las acciones resultantes de los proyectos científicos será necesario formar profesionales universitarios con capacidades innovadoras y emprendedoras, y que estos se constituyan en referentes intelectuales, tanto de la comunidad científica donde actúan como de la sociedad en la que se desenvuelven. Se precisará también que estos jóvenes profesionales universitarios logren el más alto grado posible de eficacia, eficiencia y efectividad (entendiendo por efectividad a la capacidad de elaborar, valorizar y alcanzar los objetivos propuestos) en el proceso de construcción del conocimiento necesario que les permita alcanzar aquellos logros. Estas metas, que procuran impulsar el progreso social y que implican la valorización de los objetivos, han de ser tangibles y contrastables por sus resultados en la disminución de la indi- 
gencia y la pobreza. Se espera que estos profesionales sean capaces de aplicar sus capacidades de resiliencia, o sea de resguardar todos y cada uno de los logros alcanzados en el desarrollo social a fin de enfrentar las crisis que se les presenten.

\section{Referencias bibliográficas}

Altshuller, G. S., \& Vertkin, I. (1994). Cómo convertirse en un genio. Minsk, pp. 453-468.

Aracil, J. (1995). Dinámica de sistemas. ISDEFE.

Benecke, D. W. (1973). Cooperación y Desarrollo. Ediciones Nueva Universidad.

Brown, G. S. (1990). The Genisis of the System Thinking Program at the Orange Grove Middle School. Tucson.

Bunge, M. (2012). Ontología II: Un mundo de sistemas. Gedisa.

Chesbrough, H. (2012). Innovación abierta. Innovar con éxito en el siglo XXI. Research-Technology Management, pp. 20-27.

Forrester, J. W. (1961). Industrial Dynamics. MIT Press.

- (30 de mayo de 1996). La Dinámica de Sistemas y el Aprendizaje del Alumno en la educación escolar. University of Virginia School of Education. https://pdfs.semanticscholar.org /63d4/5181cfaOef62c4811a057c22ebd360287726.pdf

Friedman, M. (1957). A Theory of the Consumption Function. Princeton University. http:// papers.nber.org/books/frie57-1

Lopes de Sá, L. F. (2008). Primeiras informações sobre o Neopatrimonialismo Contábil. https://library.org/document/z15x358y-primeiras-informacoes-sobre-o-neopatrimonialismocontabil.html

Perissé, M. C. (2011). Actos cooperativos para el desarrollo económico: un sistema de información para la economía social. Universidad Nacional de La Matanza. https://repositoriocyt. unlam.edu.ar/handle/123456789/364

(2018a). El Balance Social y el Estado de Valor Agregado. Ciencia y Técnica Administrativa. https://dialnet.unirioja.es/servlet/articulo?codigo=6523374

(2018b). Innovación y espíritu empresarial: la universidad y las redes de cooperación productiva. Ciencia y Técnica Administrativa. http://www.cyta.com.ar/biblioteca/ bddoc/bdlibros/universidad_emprendedorismo.html

(2019). Gestión en ciencia y tecnología: una perspectiva sistémica para la I+D+i. Ciencia y Técnica Administrativa. http://www.cyta.com.ar/biblioteca/bddoc/bdlibros/ management_cyt/management_cyt.htm

(2020). System Dynamics: fast guide. Ciencia y Técnica Administrativa. http:// cyta.com.ar/biblioteca/bddoc/bdlibros/dinamica_sistemas/dinamica_sistemas.htm

Schumpeter, J. A. (1997). Teoria do desenvolvimento econômico:uma investigação sobre lucros, capital, crédito, juro e o ciclo econômico. Nova Cultur. 